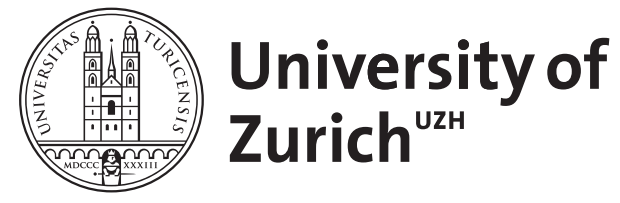
Archive

University of Zurich

University Library

Strickhofstrasse 39

CH-8057 Zurich

www.zora.uzh.ch

Year: 1993

\title{
The impact of quality and reliability on demand
}

Falkinger, Josef

DOI: https://doi.org/10.1515/jbnst-1993-5-606

Posted at the Zurich Open Repository and Archive, University of Zurich

ZORA URL: https://doi.org/10.5167/uzh-81674

Journal Article

Published Version

Originally published at:

Falkinger, Josef (1993). The impact of quality and reliability on demand. Jahrbücher für Nationalökonomie und Statistik = Journal of Economics and Statistics, 211:421-425.

DOI: https://doi.org/10.1515/jbnst-1993-5-606 


\title{
The Impact of Quality and Reliability on Demand Der Einfluß von Qualität und Zuverlässigkeit auf die Nachfrage
}

\author{
By Josef Falkinger*), Graz
}

\section{Introduction}

Are quality and quantity complements or substitutes? More precisely, does an increase of quality increase or decrease the demand for a good at a given price? Julianne Nelson (1991), defining quality as reliability, gives the following answer. Consumers treat reliability as a substitute for quantity if in the absence of risk the price elasticity of demand for the respective good is smaller than unity. If the elasticity is greater than unity, then quantity and reliability are complements.

The present paper puts forward a more general model which shows essentially three things. First, it is important to distinguish clearly between reliability on the one side and level of quality on the other side. Secondly, while the elasticity rule presented in Nelson (1991) is valid if the effects on demand of changes in the level of quality are considered, quantity and reliability are more often complements than suggested by that rule. Finally, for many types of demand curves (for instance for all concave or linear demand curves) an increase in reliability definitely leads to higher demand regardless of the value of price elasticity at the relevant point.

\section{Quality Versus Reliability}

Consider a consumer who purchases $\mathbf{x}$ units of a good of variable quality $\widetilde{\mathrm{q}}$, where "variable quality" means that $\mathrm{x}$ units of the good provide a random level of service $\widetilde{z}=$ qx. Denote by D the relevant range of possible quality levels (depending on the considered distributions of $\tilde{\mathrm{q}}$ ). Assume that the consumer's preferences can be represented by a quasilinear utility function. (This assumption is justified when the considered good represents only a small share of consumer expenditure so that the income effect is negligible). Then maximization of expected utility with respect to $\mathrm{x}$ yields the first-order-condition:

$$
\mathrm{F} \equiv \partial \mathrm{Eu}(\widetilde{\mathrm{q}} \mathrm{x}) / \partial \mathrm{x}-\mathrm{p}=0
$$

$\left.{ }^{*}\right)$ I wish to thank J. K. Brunner, R. Winter-Ebmer and the participants of the research seminar at the University of Linz for helpful suggestions. 
where $\mathrm{E}$ is the expectation operator, $\mathrm{u}$ is the utility function regarding $\mathrm{z}=\mathrm{qx}$, and $\mathrm{u}^{\prime}>$ $0, \mathrm{u}^{\prime \prime}<0$ is assumed.

Nelson (1991) concentrates on the special case that $\widetilde{\mathrm{q}}$ is distributed as follows: $\widetilde{\mathrm{q}}=1$ with probability $\pi$, and $\widetilde{\mathrm{q}}=\mathrm{a}$ with probability $1-\pi$, for some $\mathrm{a}<1$. For this case, first-order-condition (1) reduces to the equation

$$
\pi \mathrm{u}^{\prime}(\mathrm{x})+(1-\pi) \mathrm{au}^{\prime}(\mathrm{ax})-\mathrm{p}=0
$$

The impact on demand $\mathrm{x}$ of reliability, interpreted as the probability of full service, $\pi$, can be calculated by implicit differentiation of (2). The following sufficient conditions are derived in Nelson (1991): Let $\alpha(\mathrm{z}) \equiv-\mathrm{u}^{\prime \prime}(\mathrm{z}) \mathrm{z} / \mathrm{u}^{\prime}(\mathrm{z})$ be the elasticity of marginal utility of $z$. Let $z(p)$ be the demand curve for service $z$ defined by $u^{\prime}(z)=p$ and let $\varepsilon(z) \equiv$ $-z^{\prime} p / z$ be the price elasticity of demand at $z$ (by definition, $\left.\varepsilon(z)=1 / \alpha(z)\right)$. Them, $\partial x / \partial \pi$ $>0$ if, for all $\mathrm{z} \in[\mathrm{ax}, \mathrm{x}], \alpha(\mathrm{z})<1(\varepsilon(\mathrm{z})>1$, resp.). $\partial \mathrm{x} / \partial \pi<0$ if, for all $\mathrm{z} \in[\mathrm{ax}, \mathrm{x}], \alpha(\mathrm{z})>1$ $\left.(\varepsilon(\mathrm{z})<1, \text { resp. })^{1}\right)$.

Obviously, the more general problem is: Given that the quality of a product is not fixed but distributed according to some distribution function $\mathrm{G}$. How reacts demand to changes in G? Especially, the following two aspects are of interest. First, how reacts demand to a shift of quality, and secondly, how is demand affected by changes in the quality risk? The next section, dealing with the impact of quality on demand, analyzes the first question. Section 4, dealing with the impact of reliability on demand, answers the second question.

\section{The Impact of an Increasing Quality Level on Demand}

Suppose that $\widetilde{\mathrm{q}}$ is shifted to $\widetilde{\mathrm{q}}^{\mathrm{r}}=\widetilde{\mathrm{q}}+\mu$ where $\mu$ is a positive real number. Then, first-order-condition $(1)$ reads: $\partial \mathrm{E}[\mathrm{u}((\widetilde{\mathrm{q}}+\mu) \mathrm{x})] / \partial \mathrm{x}-\mathrm{p}=0$. Using $\partial \mathrm{Eu} / \partial \mathrm{x}=\mathrm{E} \partial \mathrm{u} / \partial \mathrm{x}$, one gets

$$
\mathrm{F} \equiv \mathrm{E}\left[\mathbf{u}^{\prime}((\widetilde{\mathrm{q}}+\mu) \mathbf{x})(\widetilde{\mathrm{q}}+\mu)\right]-\mathrm{p}=0 .
$$

Implicit differentiation of (3) gives us the following proposition.

Proposition 1: Let $\mathrm{x}(\mathrm{p}, \mu)$ be the demand curve corresponding to (3). Then, $\partial \mathrm{x} / \partial \mu>0$ $(=,<0)$ if, for all $\mathrm{q} \in \mathrm{D}, \varepsilon(\mathrm{qx})>1(=,<1$, resp.).

Proof: According to (3), $\partial \mathrm{x} / \partial \mu=-\mathrm{F}_{\mu} / \mathrm{F}_{\mathrm{x}}$. Since $\mathrm{F}_{\mathrm{x}}<0$, because of $\mathrm{u}^{\prime \prime}<0$, we have: $\partial \mathrm{x} / \partial \mu>,=,<0$ iff $\mathrm{F}_{\mu}>,=,<0$, respectively. Differentiation of (3) with respect to $\mu$, yields $\mathrm{F}_{\mu}=\mathrm{E}\left[\mathrm{u}^{\prime}((\widetilde{\mathrm{q}}+\mu) \mathrm{x})+\mathrm{u}^{\prime \prime}((\widetilde{\mathrm{q}}+\mu) \mathrm{x})(\widetilde{\mathrm{q}}+\mu) \mathrm{x}\right]$. Now, the square-bracketed term is positive, zero, or negative at same point $\mathrm{z} \in \mathrm{xD}$ if $\alpha(\mathrm{z})<,=,>1$, respectively. Use $\varepsilon(\mathrm{z})=$ $1 / \alpha(z)$ to get from this to the sufficient condition given in the proposition. Q.E.D.

It should be noticed that the sufficient condition described by Proposition 1 is the same as the one presented by Nelson (1991). However, here it characterizes the impact on demand of shifts in the quality level and not of changes in reliability. With regard to the latter see the analysis of the next section.

1) The given sufficient condition is, of course, no necessary condition. For instance, it is interesting to notice that $\partial \mathrm{x} / \partial \pi>0$ if $a=0$, as implicit differentiation of $(2)$ for $a=0$ shows. That means, if the risk is total breakdown, then an increase of reliability is always complementary to quantity. 


\section{The Impact of Reliability on Demand}

Assign to all $\widetilde{\mathrm{q}}$, with given mean quality $\overline{\mathrm{q}}$, a reliability index $\varrho$ which is inversely related to the risk of $\widetilde{\mathrm{q}}$. That is, if $\varrho\left(\widetilde{\mathrm{q}}^{\mathrm{c}}\right)>\varrho(\widetilde{\mathrm{q}})$, then $\widetilde{\mathrm{q}}^{\mathrm{s}}$ is less risky than $\widetilde{\mathrm{q}}$ in the sense of the Rothschild-Stiglitz ordering of risks. The following proposition presents sufficient conditions for the impact of increasing reliability (that is, decreasing quality risk) on demand.

Proposition 2: Define $\beta(\mathrm{z}) \equiv-\mathrm{u}^{\prime \prime \prime}(\mathrm{z}) \mathrm{z} / \mathrm{u}^{\prime \prime}(\mathrm{z})$. Let $\mathrm{x}(\mathrm{p}, \varrho)$ be the demand curve resulting from $(1)$ if reliability of $\widetilde{q}$ is $\varrho$. Then, $x$ increases (remains constant, decreases) with $\varrho$ if, for all $\mathrm{q} \in \mathrm{D}, \beta(\mathrm{qx})<2(=,>2$, resp.).

Proof: Let $\varrho\left(\widetilde{\mathrm{q}}^{c}\right)>\varrho(\widetilde{\mathrm{q}})$. According to the Rothschild-Stiglitz ordering of risks, the expectation of a strictly concave (linear, convex) function decreases (is constant, increases) with increasing risk ? $\left.{ }^{2}\right)$ Thus, we have $E\left[u^{\prime}\left(\widetilde{q}^{6} x\right) \widetilde{q}^{c}\right]>,=,<E\left[u^{\prime}(\widetilde{q} x) \hat{q}\right]$ if $\mathrm{u}^{\prime}(\mathrm{qx}) \mathrm{q}$ is concave, linear, convex in $\mathrm{q}$, respectively. Using this in (3) (with $\mu=0$ ) and taking into account that $\mathrm{F}_{\mathrm{x}}<0$, we get $\mathrm{x}\left(\mathrm{p}, \varrho\left(\widetilde{\mathrm{q}}^{\mathrm{c}}\right)\right)>,=,<\mathrm{x}(\mathrm{p}, \varrho(\widetilde{\mathrm{q}}))$ if, for all $\mathrm{q} \in \mathrm{D}$, $\partial^{2}\left[u^{\prime}(q x) q\right] / \partial q^{2}<,=,>0$, respectively. Calculation yields $\partial^{2}\left[u^{\prime}(q x) q\right] / \partial q^{2}=\left[2 u^{\prime \prime}(q x)\right.$ $\left.+\mathrm{u}^{\prime \prime \prime}(\mathrm{qx}) \mathrm{qx}\right] \mathrm{x}$. Thus, $\partial^{2}\left[\mathrm{u}^{\prime}(\mathrm{qx}) \mathrm{q}\right] / \partial \mathrm{q}^{2}<,=,>0$ iff $\beta(\mathrm{qx})<,=,>2$, respectively. Q.E.D.

Proposition 2 characterizes the impact on demand of reliability (in contrast with the impact of quality shifts characterized by Proposition 1). However, the characterization is not easy to interprete since $\beta$ is not an established economic magnitude. The following Lemma allows us to relate $\beta$ with the familiar parameters $\alpha$ and $\varepsilon$.

Lemma: For $\alpha(\mathrm{z}) \equiv-\mathrm{u}^{\prime \prime}(\mathrm{z}) \mathrm{z} / \mathrm{u}^{\prime}(\mathrm{z}), \varepsilon(\mathrm{z}) \equiv-\mathrm{z}^{\prime} \mathrm{p} / \mathrm{z}$ and $\beta(\mathrm{z}) \equiv-\mathrm{u}^{\prime \prime \prime}(\mathrm{z}) \mathrm{z} / \mathrm{u}^{\prime \prime}(\mathrm{z})$ holds: $\beta(\mathrm{z})<,=,>1+\alpha(\mathrm{z})$ iff $\mathrm{d} \alpha / \mathrm{dz}>,=,<0$, respectively.

Proof: By definition, $\mathrm{d} \alpha / \mathrm{dz}=-\left(\mathrm{u}^{\prime \prime \prime} \mathrm{z}+\mathrm{u}^{\prime \prime}\right) / \mathrm{u}^{\prime}+\left(\mathrm{u}^{\prime \prime} / \mathrm{u}^{\prime}\right)^{2} \mathrm{z}=-\left(\mathrm{u}^{\prime \prime} / \mathrm{u}^{\prime}\right)\left(\mathrm{u}^{\prime \prime} \mathrm{z} / \mathrm{u}^{\prime \prime}+1-\right.$ $\left.u^{\prime \prime} z / u^{\prime}\right)=-u^{\prime \prime} / u^{\prime}(-\beta+1+\alpha)$. since $u^{\prime}>0, u^{\prime \prime}<0$, the Lemma follows. Q.E.D.

With this Lemma we get immediately the following corollary to Proposition 2.

Proposition 3: Let $\mathrm{z}(\mathrm{p})$ be the demand curve for service $\mathrm{z}$, defined by $\mathrm{p}=\mathrm{u}^{\prime}(\mathrm{z})$. Let $\varepsilon(\mathrm{z}) \equiv-\mathrm{z}^{\prime} \mathrm{p} / \mathrm{z}$.

i) If $z(p)$ is isoelastic, then

$\mathrm{x}$ increases (remains constant, decreases) with $\varrho$ if $\varepsilon>1$ (=, $<1$, resp.).

ii) For demand curves with $\mathrm{d} \varepsilon / \mathrm{dz}<0$,

$x$ increases with $\varrho$ if, for all $q \in D, \varepsilon(q x) \geq 1$.

iii) For demand curves with $\mathrm{d} \varepsilon / \mathrm{dz}>0$,

$\mathrm{x}$ decreases with $\varrho$ if, for all $\mathrm{q} \in \mathrm{D}, \varepsilon(\mathrm{qx}) \leq 1$.

Proof: Since $\alpha(\mathrm{z})=1 / \varepsilon(\mathrm{z})$, the above Lemma can be rewritten in the form: $\beta(\mathrm{z})<$, =, $>1+1 / \varepsilon(\mathrm{z})$ iff $\mathrm{d} \varepsilon / \mathrm{dz}<,=,>0$, respectively. Combining this with Proposition 2, one gets the given sufficient conditions. Q.E.D.

Proposition 3 has a clear economic interpretation. The sufficient conditions for the impact of reliability are similar to, though less general than, those of Proposition 1 which characterizes the impact of the quality level. In the distinguished cases, a sufficient condition for a complementary (substitutive) relationship between reliability and demand is that the demand curve is price-elastic (-inelastic, resp.) in the relevant domain. However, the sufficient conditions are far from being necessary. Therefore, it is not at all clear whether or not unity is really that threshold value for the price-elasticity, which decides on the impacts of reliability as well as of the quality

2) Cf. e.g. Hey (1981), p. 29. 
levels. The analysis in the next section precises this point and clarifies the situation for a wide range of demand curves.

\section{Examples}

Example 1: Concave or linear demand curves for service $\mathrm{z}$.

$\mathrm{z}^{\prime \prime} \leq 0$ implies $\mathrm{u}^{\prime \prime \prime} \leq 0$. Thus, by definition, $\beta \leq 0$, since $\mathrm{u}^{\prime \prime}<0$. With Proposition 2 we conclude that reliability always increases demand for services with concave or linear demand curves. In contrast with that, an increasing quality level may increase or decrease demand, according to Proposition 1.

Example 2: Exponential demand curves $\mathrm{z}=\mathrm{ke}^{-\lambda \mathrm{p}}$, where $\mathrm{k}, \lambda$ are positive constants. Inverting the demand curve, one gets $\mathrm{u}^{\prime}=\mathrm{p}=(\ln \mathrm{k}-\ln \mathrm{z}) / \lambda$. Calculation gives us $\beta=$ $-\mathrm{u}^{\prime \prime \prime} \mathrm{z} / \mathrm{u}^{\prime \prime}=1$. Hence, reliability always increases demand, according to Proposition 2. The reaction of demand to the quality level depends on $\varepsilon(\mathrm{qx})$. Calculation gives us $\varepsilon=$ $\lambda \mathrm{p}=\ln \mathrm{k}-\ln (\mathrm{qx})$. Therefore, according to Proposition 1 , increasing quality levels lead to higher demand as long as $q x<k / e$ for all $q \in D$. If, for all $q \in D, q x>k / e$, then increasing quality decreases demand.

Example 3: Logarithmic demand curves $\mathrm{z}=\mathrm{A}-(1 / \sigma) \ln \mathrm{p}$ (corresponding to constant-curvature utility functions $\mathrm{u}^{\prime}=\mathrm{e}^{-\alpha(z-\mathrm{A})}$ ), where $\mathrm{A}, \sigma$ are positive constants.

Calculation gives us $\varepsilon=1 /(\sigma z)$ and $\beta=\alpha=\sigma z$. Using this in Proposition 1 and 2 , we get: As long as $\mathrm{qx}<2 / \sigma$ for $\mathrm{q} \in \mathrm{D}$, reliability increases demand, whereas increasing quality levels lead to higher demand if $\mathrm{qx}<1 / \sigma$ for all $\mathrm{q} \in \mathrm{D}$. Thus, the threshold characterizing the impact of changing quality levels is reached at a lower consumption than the relevant threshold for the impact of reliability.

Example 4: $\mathrm{u}=\mathrm{b} \ln (\mathrm{z}-\gamma)$, where $\mathrm{b}$ is a positive constant and $\mathrm{z}>\gamma \cdot \gamma>0$ corresponds to subsistence goods and $\gamma<0$ to luxuries.

Calculation yields $\beta=2 \alpha$ and $1 / \alpha=\varepsilon=1-\gamma /$ z. Thus, $\beta<,=,>2$ iff $\alpha<,=,>1$, where the latter condition is further equivalent to $\gamma<,=,>0$, respectively. Using this in Proposition 1 and 2 we get: For subsistence goods $(\gamma>0)$, quality as well as reliability are substitutes for quantity. For luxuries $(\gamma<0)$, both increasing quality levels or increasing reliability induce an increase in demand.

\section{Conclusion}

The paper has distinguished between the quality level of a product and its reliability. General characterizations of the impacts on demand of changing quality levels on the one side and varying reliability on the other side have been derived (Proposition 1-3). Application of the general characterizations to familiar types of demand curves has shown that in many situations (for concave, linear or exponential demand curves) increasing reliability unambigously leads to higher demand, whereas increasing quality levels induce higher demand at comparatively low consumption levels where demand is price-elastic. When demand becomes more saturated and price-inelastic, an increase in quality levels decreases demand. In other situations (Example 3), the impact of reliability on demand can be positive as well as negative. However, the range in which demand increases is larger if reliability is improved than if the quality level is increased. Finally, example 5 has shown that, in accordance with intuition, relatively less quantity of a subsistence good is demanded if its reliability or quality levels are increased. But for 
luxury goods, a higher level of quality or reliability means higher demand, ceteris paribus.

\section{References}

Hey, J. D. (1981), Economics in Disequilibrium. Martin Robertson, Oxford.

Nelson, J. (1991), Quality as a substitute for quantity: Do more reliable products ever sell for less? Economics Letters, 36, 239-243.

\section{Summary}

Starting from the known fact that higher product quality does not necessarily induce higher demand, the present paper shows three things. First, it is important to distinguish between quality level and reliability of a product. Secondly, it turns out that an increase of reliability increases demand more likely than a quality increase. Thirdly, for many types of demand curves (for instance, for all concave or linear demand curves) on increase of reliability unambigously leads to higher demand.

\section{Zusammenfassung}

Ausgangspunkt dieser Arbeit ist die Tatsache, daß höhere Qualität nicht notwendig zu höherer Nachfrage führt. Die Ergebnisse der durchgeführten Analyse sind: Erstens ist es wichtig, zwischen Qualität und Zuverlässigkeit eines Produktes zu unterscheiden. Zweitens stellt sich heraus, daß höhere Zuverlässigkeit eher eine höhere Nachfrage induziert als höhere Qualität. Drittens wird gezeigt, daß für viele gebräuchliche Typen von Nachfragekurven (z.B. für alle konkaven oder linearen Nachfragekurven) die Erhöhung der Zuverlässigkeit eines Produkts definitiv die Nachfrage nach dem Produkt erhöht.

Univ.-Prof. Dr. Josef Falkinger, Universität Graz, Institut für Finanzwissenschaft und Öffentliche Wirtschaft, Schubertstr. 6A, A-8010 Graz. 